\title{
Sustainable Coastal Tourism Model
}

\author{
Joseph P D*
}

\begin{abstract}
To make coastal tourism more sustainable, the researcher has developed a model for sustainable coastal tourism. The evolved model has been tested for its fitness using structural equation modelling (SEM). The analysis of the data has been done based on the perceptions of beach visitors and local community. The perceptions pertaining to economic, socio-cultural, environmental, technological and political sustainability of coastal tourism was collected using questionnaires from five different beach areas of Dakshina Kannada district of Karnataka. After the testing of the model, as to whether it is found fit, the model could be applied at any coastal tourism destination having similar profile for attaining integrated sustainability of coastal tourism destinations.
\end{abstract}

Keywords: Sustainable, Coastal, Tourism, Visitors, Holidays

\section{Introduction}

Coastal Karnataka consists of Uttara Kannada, Udupi and Dakshina Kannada, all having a coastline of $300 \mathrm{~km}$ of potential virgin beaches. This unexplored coastal area can be well utilized with a systematic and careful development approach. Sun, Sand and Sea are the three 'Mantras' that make a destination explored from unexplored, and popular from unpopular. Major part of the

\footnotetext{
* Mangalore University, Mangalagangothri, Karnataka, India; josephpallickal@gmail.com
} 
holidays around the world is connected to these three 'Mantras'. According to Bruna Alves, Wavier Benavente and Oscar Ferreira (2014),Seaside tourism and recreation have rapidly increased in recent decades, and has become 'big business' and a primary contributor to the Gross Domestic Product (GDP) of several countries. Coastlines worldwide receive millions of visitors every year for activities such as beach going, swimming, fishing, etc. Mediterranean and Caribbean coastal areas have already been identified, recognized and explored by vacationers. A coast has many motivating factors for visitors to get attracted. Coastal area or beaches have become an integral component in everyone's holidays.

Coastal areas are thickly populated worldwide putting the coastal environment in danger. This destruction of the coastal environment is caused by many activities that take place around the coastal areas of which tourism also has a leading role to play. In order to keep these areas to be useful for a variety of activities (fishing, tourism etc.) promotion and implementation of a Sustainable Development Model is the only alternative. Clean water, healthy coastal habitats, and a safe, secure, and enjoyable environment are clearly fundamental to successful coastal tourism (Houston \& James R, 1996). Countries with long coastal areas are always graced and benefitted as they have an enchanting space for tourism to flourish which leads to socio-economic development at all levels.

\section{The Research Problem}

It has been revealed from the review conducted that many studies have been carried out in the field of sustainable tourism and all of them have covered different aspects of sustainable tourism. Though, many studies have advocated the role of local people in sustainable tourism, few have explored the theoretical classifications of sustainability, yet another group of studies have focused on the impact of tourism on destinations. But the studies conducted in the area of sustainable coastal tourism are very few and limited and most of them are scientific in nature dealing with coastal destruction, sea level rise, beach erosion, beach nourishment, destruction of coastal ecology etc. Out of the studies conducted earlier, $95 \%$ are foreign studies. Very few studies are 
conducted in India that concentrates on Indian coasts. They too are scientific in nature and no serious effort has been made so far, to integrate economic, socio-cultural, environmental and political and technological sustainability elements into the sustainable coastal tourism development initiatives.

\section{Objectives of the Study}

To assess the importance and effectiveness of sustainable tourism practices in coastal areas;

1. To evolve a holistic model for sustainable coastal tourism practices based on the research; and

2. To test the fitness of the evolved model by using Structural Equation Modelling (SEM).

\section{Need for the Study}

Most coastal areas accommodate over $50 \%$ of the world population and the visitors in millions floating to the coastal areas give extra environmental pressure to this region. Coastal environments are under serious threat and their problems can no longer be avoided or deferred. This global issue has to be addressed and attended immediately to save these coastal areas from deterioration and destruction.

Many a times, tourism becomes an inevitable danger for the coastal environment because of the over use of coastal resources such as water, soil and energy and its related consequences. Normally, any development plan at a coastal area is approached from a commercial perspective leading to a biased view where environmental aspect is concerned; project managers and policy makers look at only "trying to minimize environmental effects". This attitude leads to unsustainable coastal tourism development which has multiple negative implications not only on the environment and society, but also leads to economic leakage as it destroys the physical structures such as landscape, bio-diversity and eco-system in the sea and on the land which makes up the foundation for tourism activities at coastal areas. More attention must be paid to the integration of coastal tourism through strategic development planning which will reduce problems induced by 
tourism and affect both the sustainability of the tourism industry as well as costal resources used by other sectors.

Coastal tourism being the fastest growing modern tourism puts immense pressure on the coast. As tourism continues to grow at a greater phase and gets diversified into a series of alternative forms, there originates the need to thinking about a sustainable way of tourism development especially at the coastal areas to enjoy the resources for a longer time period. UNEP Report (2009) indicates that "given the scale of tourism in world's coastal zones, one of the greatest challenges faced by coastal managers is giving tourism development a proper place within integrated coastal management in order to increase its long-term sustainability". Keeping in view of the above facts, sustainable tourism principles advocate the role of community participation in every sphere of tourism development, their socio-economic benefits, preservation of social values and tradition and surely environmental protection. There are clear legislations regarding the use of environmental resources including land, water and energy in many of the world destinations but there is an ignorance and negligence or lack of laws for the involvement of local community and the amount of socio-economic benefits extended to the community. This is being considered as a lacuna in sustainable tourism practices around global destinations.

\section{Nature and Scope of the Study}

This is an exploratory study which is focused on exploring the ways and means of developing a model for sustainable coastal tourism in the study area. The study is confined to certain select beaches of Dakshina Kannada district of Karnataka in spite of the fact that Kanataka's $300 \mathrm{Km}$ coast line is spread in two other districts, Udupi and Uttara Kannada. The researcher has selected 5 beaches in Dakshina Kannada that is Ullal, Someshwar, Thannirbhavi, Surathkal and Panambur in order to conduct the survey and to draw meaningful conclusions. These are the beaches having great tourism potential but are untapped and unexplored fully from the tourism point of view. 


\section{Sustainable Coastal Tourism Model}

On the basis of UNWTO's guidebook, 'Indicators of Sustainable Development of Tourist Destinations' and the review of literature, a holistic model for sustainable coastal tourism were developed by the researcher. The developed model was tested with Structural Equation Modelling (Confirmatory Factor Analysis) to check the extent of fitness of sustainability factors to the prescribed model. The model is presented below in the form of a diagram.

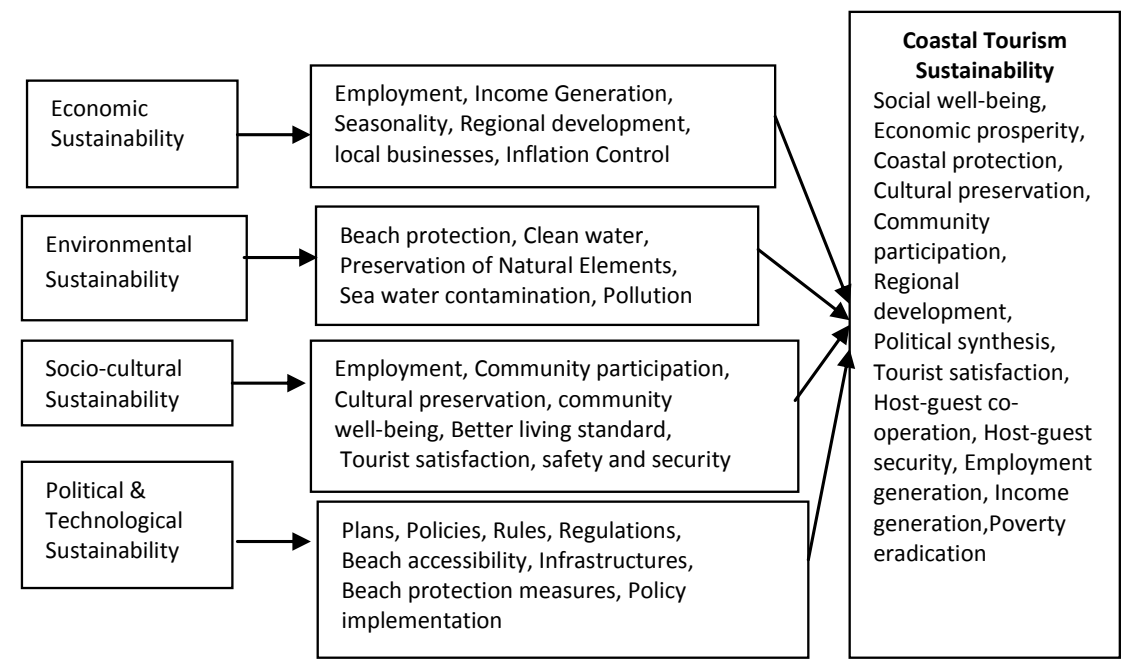

Fig1: Sustainable Coastal Tourism Model

Source: Designed by the researcher based on the UNWTO's guidebook- Indicators of Sustainable Development of Tourist Destinations \& Review

\section{Research Methodology}

Quantitative data has been used by the researcher in developing this model and subsequently getting its fitness tested. Quantitative data was collected by administering questionnaires to local community and beach visitors. Questionnaires were arranged in 5 point Likert scale including questions pertaining to all aspects of sustainability. Questionnaires were framed in two languages (English and Kannada) in order to clearly convey the meaning of the questions to the respondents. Data collected from the respondents was analyzed using Structural Equations Modelling to test the extent of fitness of the model. Description of the sample id given below: 


\section{Local Community}

This includes the residents of the beach area. Since local community has a crucial role in the sustainable tourism practices, this was a major part of the survey. Survey was done with the help of questionnaires by using 5 point Likert Scale. Apart from the demographic details, the impacts of tourism at coastal areas, their role and benefits were mainly included in the survey. Local residents of 5 beaches in Dakshina Kannada were selected for the survey, which included Someshwar, Ullal, Thannirbhavi, Panambur and Surathkal beach area.

A total of 200 questionnaires were collected from 5 beach areas, 40 from each beach area. Though different strata were included as 5 beaches, it is a non-probability sampling and the method adopted for determining the sample size and selection of the sample was convenience sampling method. A sample size of 200 was decided based on an assumption that it is adequate enough to represent the entire population. The questionnaires were printed both in English and Kannada since many of the respondents were not able to follow English.

Beach Visitors: This segment of respondents included the heterogeneous group of people visiting different beaches of Dakshina Kannada. The main concentration of this survey was to find the difference between their expectations and satisfaction. Survey was done with the help of questionnaires by using 5 point Likert Scale. Beach visitors from 5 beaches Someshwar, Ullal, Thannirbhavi, Panambur and Surathkal beach area in Dakshina Kannada were selected for the survey.

A total of 350 questionnaires were collected from 5 beach areas at the rate of 70 from each beach. Out of the total questionnaires collected, only 313 were usable for the study. Remaining questionnaires which were incomplete and illogically filled had to be rejected. Though different strata were included in the 5 beaches, the method was a non-probability sampling and the method adopted for determining the sample size and selection of the sample was convenience sampling method. A sample size of 350 was decided based on the assumption that it is adequate enough to represent the entire population. The questionnaires were printed 
both in English and Kannada since some of the respondents were not able read or write English. This study also incorporated secondary research methods to determine the research objectives based on the research gap identified through the process of literature review. As part of the literature review, the researcher has depended on books, journal articles, thesis and projects, reports of various related organizations, website contents etc. It is only through the literature survey, different variables leading to the sustainability of beach destinations have been finalized.

\section{Testing of the Model}

The prescribed model for sustainable coastal tourism was tested by using Structural Equation Modelling (SEM) - Confirmatory Factor Analysis. This was carried out separately for visitor perceptions and community perceptions on four different aspects of sustainable coastal tourism.

\section{Structural Equation Modelling (SEM)}

Structural Equation Modelling (SEM) is a statistical model test that explains the relationship between/among multiple variables. This model explains the interrelationship among constructs. This measurement model's foundation lies in two types of multivariate techniques such as factor analysis and multiple regression analysis. Structural modelling shows the relationship between latent constructs using paths. For measuring the beach sustainability based on the perceptions of the beach visitors and local community, Structural Equation Modelling was adopted to analyze the data. In order to estimate the relationship, the following statistical matrices were employed.

\section{Root Mean Square Error of Approximation (RMSEA)}

RMSEA was used to measure the attempts to correct the tendency of the $\mathrm{X}^{2}$ Goodness of FIT (GOF) statistics so as to reject models with a large sample, or a large number of observed variables is also known as the RMSEA. Lower RMSEA value indicates that the model is a better fit (Hair, Black, Babin \& Anderson, 2010). By convention, there is a good model fit if RMSEA is less than or equal to 0.05 . However, there is an adequate fit if RMSEA is less than or equal to 0.08 . 


\section{Comparative Fit Index (CFI)}

Comparative Fit Index (CFI) compares the existing model with a null model which assumes the latent variable in the model are uncorrelated. By convention, CFI should be equal to or greater than 0.90 to accept the model, indicating that $90 \%$ of the co-variation in the data can be produced by the given model.

\section{Tucker Lewis Index (TLI)}

TLI equals the difference between the chi-square of the null model and chi-square of the target model.

\section{Goodness of - Fit Index (GFI)}

Goodness of - Fit Index (GFI) measures the fit function of the conceptual model. GFI varies from 0 to 1 . Values close to 1 indicates better fit.

\section{Validation of the Measurement Model}

In order to test the validity of measurement model, the following test has been used.

\section{Confirmatory Factor Analysis (CFA)}

Factor Analysis is an independent technique which helps to define the underlying structure among the variables in the analysis. Factor Analysis provides the tools for analyzing the structure of the interrelationships (correlations) among a large number of variables. These variables are called factors. These groups of variables may be highly correlated and hence Factor Analysis can be used for multiple purposes. Factor Analysis helps in data deduction and, if used well, can help in measuring on a conceptual basis the understanding of the relationship between variables. Hence Factor Analysis helps in giving meaning to the collective representation of variables.

\section{Goodness of Fit Index for Tourist Perceptions}

Measurement Model -Economic Sustainability

The following table portrays the result of the model fit test done on economic sustainability of coastal tourism. 
Table 1 Confirmatory Factor Analysis for economic sustainability of Coastal Tourism

\begin{tabular}{lr}
\hline Fit Indices & Value \\
\hline Chi Square Statistics & 53.63 \\
Degree of Freedom & 13 \\
P. Value & Significant $(\mathrm{P}<.001)$ \\
RMSEA & 0.061 \\
CFI & .891 \\
TLI & .092 \\
\hline
\end{tabular}

Table 1 shows the measurement model economic sustainability that has a chi-square value of 53.63 with 13 degrees of freedom and a Pvalue of less than 0.001, which is significant. The value of RMSEA and absolute fit index is 0.061.This is within the guideline of less than 0.08 for a model of this complexity and size. Thus the RMSEA value supports this model well. The CFI value of 0.891 is slightly higher than the required limit of 0.90 and TLI is 0.92 , which is also within the recommended guidelines of 0.90 . Hence, the Confirmatory Factor Analysis (CFA) results suggest that the economic sustainability model provides acceptable fit for the data. This factor showed significant $(\mathrm{p}<0.001)$ loadings on all three variables in the designed construct.

\section{Measurement Model - Environment Sustainability}

The following table portrays the result of the model fit test done on environment sustainability of coastal tourism.

Table 2 Confirmatory Factor Analysis for environment sustainability of Coastal Tourism

\begin{tabular}{lr}
\hline Fit Indices & Value \\
\hline Chi Square Statistics & 73.51 \\
Degree of Freedom & 15 \\
P. Value & Significant $(\mathrm{P}<.001)$ \\
RMSEA & 0.060 \\
CFI & .912 \\
TLI & .071 \\
\hline
\end{tabular}

Note. $\mathrm{p}<0.01$

Source: Field Survey

Table 2 shows the measurement model for environmental sustainability that has a chi square value of 73.51 with 15 degrees of 
freedom and a p-value of less than 0.001 , which is significant. The value of RMSEA and absolute fit index is 0.060.This is within the guideline of less than 0.08 for a model of this complexity and size. Thus, the RMSEA value supports this model well. The CFI value of 0.912 is slightly higher than the required limit of 0.90 and TLI is 0.71, which is also close to the recommended guidelines of 0.90 . Hence the Confirmatory Factor Analysis (CFA) results suggest that the environmental sustainability model provides acceptable fit for the data. This factor showed significant $(p<0.001)$ loadings on all eight variables in the designed construct.

\section{Measurement Model - Socio-cultural Sustainability}

The following table portrays the result of the model fit test done on Socio-cultural sustainability of coastal tourism.

Table 3 Confirmatory Factor Analysis for Socio-cultural sustainability of Coastal Tourism

\begin{tabular}{lr}
\hline Fit Indices & Value \\
\hline Chi Square Statistics & 24.01 \\
Degree of Freedom & 2 \\
P. Value & Significant $(\mathrm{P}<.001)$ \\
RMSEA & 0.063 \\
CFI & .813 \\
TLI & .90 \\
\hline
\end{tabular}

Note. $\mathrm{p}<0.01 \quad$ Source: Field Survey

Table 3 shows the measurement model for socio-cultural sustainability that has a chi square value of 24.01 with 2 degrees of freedom and a p-value of less than 0.01 , which is significant. The value of RMSEA and absolute fit index is 0.063.This is within the guideline of less than 0.08 for a model of this complexity and size. Thus the RMSEA value supports this model well. The CFI value of 0.813 is within the required limit and TLI is 0.90 which is also within the recommended guidelines of 0.90 . Hence the Confirmatory Factor Analysis (CFA) results suggest that the sociocultural sustainability model provides acceptable fit for the data. This factor showed significant $(\mathrm{p}<0.001)$ loadings on all eleven variables in the designed construct. 


\section{Measurement Model - Political and Technological Sustainability}

The following table portrays the result of the model fit test done on Political and Technological sustainability of coastal tourism.

Table 4 Confirmatory Factor Analysis for political and Technological sustainability of Coastal Tourism.

\begin{tabular}{lr}
\hline Fit Indices & Value \\
\hline Chi Square Statistics & 58.75 \\
Degree of Freedom & 18 \\
P. Value & Significant $(\mathrm{P}<.001)$ \\
RMSEA & 0.071 \\
CFI & .932 \\
TLI & .91 \\
\hline
\end{tabular}

Note. $\mathrm{p}<0.01$

Source: Field Survey

Table 4 shows the measurement model for political and technological sustainability that has a chi square value of 54.75 with 14 degrees of freedom and a p-value of less than 0.001, which is significant. The value of RMSEA and absolute fit index is 0.071 .This is within the guideline of less than 0.08 for a model of this complexity and size. Thus the RMSEA value supports this model well. The CFI value of 0.932 is slightly higher than the required limit of 0.90 and TLI is 0.91 , which is also within the recommended guidelines of 0.90 . Hence the Confirmatory Factor Analysis (CFA) results suggest that the political \&technological sustainability model provides acceptable fit for the data. This factor showed significant $(p<0.001)$ loadings on all seven variables in the designed construct.

Goodness of Fit Index for Structural Model for Tourist Perceptions

The Model Fit for Coastal Tourism based on Visitor Perceptions 
Table 5 Goodness of Fit Index for Structural Model for Tourist Perceptions

\begin{tabular}{lr}
\hline Fit Indices & Value \\
\hline Chi Square Statistics & 312.96 \\
Degree of Freedom & 41 \\
P. Value & Significant $(P<.001)$ \\
RMSEA & .086 \\
CFI & .813 \\
TLI & .891 \\
\hline
\end{tabular}

Note. $\mathrm{p}<0.01$

Source: Field Survey

Table 5 shows the model fit for sustainable coastal tourism based on visitor perceptions. The chi-square value is 312.96 with 41 degrees of freedom $(p<0.001)$. The value of RMSEA is 0.086 , hence RMSEA value provides acceptable fit for the structural model for sustainable coastal tourism model based on visitor perceptions. The CFI is 0.813 and TLI is 0.891 . Values for both incremental fit indices are within the acceptable limit of structural model and hence the model is stable and valid. The results show that the structural model for sustainable coastal tourism based on visitor perceptions provides acceptable overall fit for the data.

\section{Goodness of Fit Index for Community Perception}

\section{Measurement Model - Economic Sustainability}

The following table portrays the result of the model fit test done on economic sustainability of coastal tourism based on community perceptions.

Table 6: Confirmatory Factor Analysis for economic sustainability of Coastal Tourism

\begin{tabular}{lr}
\hline Fit Indices & Value \\
\hline Chi-Square Statistics & 73.84 \\
Degree of Freedom & 16 \\
P. Value & Significant $(\mathrm{P}<.001)$ \\
RMSEA & 0.789 \\
CFI & .832 \\
TLI & .067 \\
\hline
\end{tabular}

Note. $\mathrm{p}<0.01$

Source: Field Survey

Table 6 shows the measurement model for economic sustainability that has a chi-square value of 73.84 with 16 degrees of freedom and a P-value of less than 0.001 , which is significant. The value of 
RMSEA and absolute fit index is 0.789. This is within the guideline of 0.08 for a model of this complexity and size. Thus the RMSEA value supports this model. The CFI value of 0.832 is also within the required limit of $0.90 \mathrm{and}$ TLI is 0.067 which is slightly less than the recommended guidelines of 0.90 . Hence the Confirmatory Factor Analysis (CFA) results suggest that the economic sustainability model provides reasonable fit for the data. This factor showed significant $(\mathrm{p}<0.001)$ loadings on all 13 variables in the designed construct.

\section{Measurement Model - Environment Sustainability}

The following table portrays the result of the model fit test done on environment sustainability of coastal tourism based on community perceptions.

Table 7 Confirmatory Factor Analysis for environmental sustainability of Coastal Tourism

\begin{tabular}{lr}
\hline Fit Indices & Value \\
\hline Chi-Square Statistics & 81.61 \\
Degree of Freedom & 21 \\
P. Value & Significant $(\mathrm{P}<.001)$ \\
RMSEA & 0.611 \\
CFI & .734 \\
TLI & .097 \\
\hline
\end{tabular}

Note. $\mathrm{p}<0.01$

Source: Field Survey

Table 7 shows the measurement model for environmental sustainability has a chi-square value of 81.61 with 21 degrees of freedom and a p-value of less than 0.001 , which is significant. The value of RMSEA and absolute fit index is 0.611 .This is within the guideline of 0.08 for a model of this complexity and size. Thus the RMSEA value supports this model. The CFI value of 0.734 is also within the required limit of 0.90 and TLI is 0.097 which is also within the recommended guidelines of 0.90 . Hence the confirmatory factor analysis (CFA) results suggest that the environmental sustainability model provides acceptable fit for the data. This factor showed significant $(p<0.001)$ loadings on all thirteen variables in the designed construct. 


\section{Measurement Model - Socio-Cultural Sustainability}

The following table portrays the result of the model fit test done on socio-cultural sustainability of coastal tourism based on community perceptions.

Table 8 Confirmatory Factor Analysis for socio-cultural sustainability of Coastal Tourism

\begin{tabular}{lr}
\hline Fit Indices & Value \\
\hline Chi-Square Statistics & 61.43 \\
Degree of Freedom & 14 \\
P. Value & Significant $(\mathrm{P}<.001)$ \\
RMSEA & 0.613 \\
CFI & .857 \\
TLI & .091 \\
\hline
\end{tabular}

Note. $\mathrm{p}<0.01$

Source: Field Survey

Table 8 shows the measurement model for socio-cultural sustainability that has a chi-square value of 61.43 with 14 degrees of freedom and a p-value of less than 0.001 , which is significant. The value of RMSEA and absolute fit index is 0.613.This is within the guideline of less than 0.08 for a model of this complexity and size. Thus the RMSEA value supports this model well. The CFI value of 0.857 is within the required limit of 0.90 and TLI is 0.091 which is also within the recommended guidelines of 0.90 . Hence the Confirmatory Factor Analysis (CFA) results suggest that the sociocultural model provides acceptable fit for the data. This factor showed significant $(p<0.001)$ loadings on all twenty two variables in the designed construct.

\section{Measurement Model - Political and Technological Sustainability The following table portrays the result of the model fit test done on socio-cultural sustainability of coastal tourism based on community perceptions.}


Table 9 Confirmatory Factor Analysis for political \& Technological sustainability of Coastal Tourism

\begin{tabular}{lr}
\hline Fit Indices & Value \\
\hline Chi-Square Statistics & 81.31 \\
Degree of Freedom & 18 \\
P. Value & Significant $(\mathrm{P}<.001)$ \\
RMSEA & 0.811 \\
CFI & .910 \\
TLI & .087 \\
\hline
\end{tabular}

Note. $\mathrm{p}<0.01$

Source: Field Survey

Table 9 shows the measurement model for political and technological sustainability that has a chi-square value of 81.31 with 18 degrees of freedom and a p-value of less than 0.001, which is significant. The value of RMSEA and absolute fit index is 0.811.This is slightly higher than the guideline of 0.08 for a model of this complexity and size. Thus the RMSEA value reasonably supports this model. The CFI value of 0.910 is also slightly higher than the required limit of 0.90 and TLI is 0.087 , which is very close to the recommended guidelines of 0.90 . Hence the Confirmatory Factor Analysis (CFA) results suggest that the political \& technological sustainability model provides acceptable fit for the data. This factor showed significant $(\mathrm{p}<0.001)$ loadings on all eight variables in the designed construct.

\section{Goodness of Fit Index - Community Perceptions}

The following Table shows the model fit for coastal sustainable tourism based on Community Perceptions.

Table 10: Goodness of Fit Index for Structural Model for Coastal Sustainable Tourism based on Community Perceptions

\begin{tabular}{lr}
\hline Fit Indices & Value \\
\hline Chi Square Statistics & 291.65 \\
Degree of Freedom & 41 \\
P. Value & Significant $(\mathrm{P}<.001)$ \\
RMSEA & .081 \\
CFI & .761 \\
TLI & .823 \\
\hline
\end{tabular}

Note. $\mathrm{p}<0.01$

Source: Field Survey

It is revealed from the analysis of the data given above that the chi square value is 291.65 with 41 degrees of freedom $(p<0.001)$. The 
value of RMSEA is 0.081, which is slightly higher than the recommended value and hence RMSEA value provides reasonable fit for the structural model for Coastal Sustainable Tourism based on Community Perceptions. The CFI is 0.761 and TLI is 0.823 . Value for both incremental fit indices is within the acceptable limit of structural model and hence the model is stable and valid. The results show that the structural model for Coastal Sustainable Tourism based on Community Perceptions provides acceptable overall fit for the data.

\section{Conclusion}

Structural Equation Modelling is done to check the extent of fitness of the sustainability factors at any similar destination. As it is found fit, this model could be applied at any coastal tourism destination having similar profile for attaining integrated sustainability of coastal tourism destinations.

\section{References}

Alves, B., Benavente, J., \& Ferreira, Ó. (2014). Beach users' profile, perceptions and willingness to pay for beach management in Cadiz (SW Spain). Journal of Coastal Research, 70(sp1), 521-526.

Brown, K., \& Tompkins, E.L.(2002). Making Waves: Integrating coastal conservation and development. London: Earthscan Publications Limited.

Honey, M. \& Krantz, D. (2007). Global Trends in Coastal Tourism.Washington: Marine Program World Wildlife Fund.

Houston, \& James, R. (1996). International Tourism and US Beaches. Retrieved on Oct. 23,2014fromResearchGatehttps:// www.researchgate.net/publication/235146233_International_Tou rism_and_US_Beaches.

Lawal Mohammed, L.\& Marafa. (2008). Integrating Sustainable Tourism Development inCoastal and Marine Zone Environment. Retrieved July 02, 2015, from https:/ / etudescaribeennes.revues.org

UNEP. (2009). Sustainable Coastal Tourism-An integrated planning and management approach. Milan: UNEP Manuals on Sustainable Tourism. 